\title{
NUMERICAL INVESTIGATION AND COST ANALYSIS OF FRP- CONCRETE UNIDIRECTIONAL HYBRID SLABS
}

\author{
Amir MAHBOOB* and Amir Reza ESKENATI \\ Strength of Materials and Structural Engineering Department, Polytechnic University of Catalonia \\ Colom 11, TR45, 08222 Terrassa, SPAIN \\ E-mail: amir.mahboob@upc.edu \\ Soheil MORADALIZADEH \\ Department of Continuum Mechanics and Structures, Escuela de Caminos, Canales y Puertos \\ Universidad Politécnica de Madrid, 28040 Madrid, SPAIN
}

\begin{abstract}
Fiber-reinforced polymer (FRP) has been commonly used to reinforce concrete structures. The kinds of FRP demonstrate an effective alternative to various methods of reinforcement in concrete structures subjected to bad environmental conditions which cause corrosion and damage to concrete. Due to their lightweight, high strength, and high corrosion and fatigue resistance, Fiber Reinforced Polymer (FRP) composites have been widely applied in steel substitution during revitalization interventions. This paper presents numerical three-points bending tests on different models to investigate the effect of the reinforcements; Carbon, Glass, and Aramid fibers to find the corresponding cost of each one. Also, there is an available experimental model for verifying the results of the FEM that demonstrated broad agreement with the experimental statement, concerning the load-displacement curve. After validating the models, alternative designs such as type of the FRP, position of the FRP, and amount of the FRP usage were numerically tested to study the influence of each on the load-bearing capacity. The results showed that the best configuration would be one with GFRP and the load-bearing capacity is around $9 \mathrm{kN}$ in the optimum design.
\end{abstract}

Keywords: CFRP, GFRP, AFRP, hybrid slabs, numerical simulation, costs.

\section{Introduction}

Concrete structures have a long-time stability and strength needs to be reinforced with a new method of construction and building system. Fiber-reinforced polymer is a novel material in the civil engineering system. A concrete slab is an important member of a building and it is required to be reinforced and strengthened. For the design of concrete slabs, the impact of both static and dynamic vertical loads should be considered. Effect load is a kind of impulsive dynamic load that is neglected in the slab design phase as other structural members $[1,2]$.

Based on recent studies, many researchers have proposed using the FRP material to reinforce and strengthen hybrid structures such as concrete elements. Subsequently, the definition and design concepts of hybrid FRP-concrete slabs were investigated and the advantages and disadvantages of the usual reinforced concrete slabs were evaluated and examined. Reinforcing and strengthening of concrete members leads to increased flexural capacity [3]. Many researchers have studied the behavior of concrete members that were reinforced and strengthened with FRP [4, 5]. Among these works, Sami [6] tested concrete slabs bonded with a composite externally and he saw a significant increase in flexural capacity. Ebead and Marzouk [7] used two types of FRP, CFRP, and GFRP to strengthen two-way concrete slabs in flexure. Toutanji et al. [8] studied concrete beams strengthened with three or six layers of CFRP. The capacity of the beams went up to $170.2 \%$ in comparison with the unreinforced beam. Hawileh et al. [9] used the mixture of externally bonded hybrid

\footnotetext{
${ }^{*}$ To whom correspondence should be addressed
} 
GFRP and CFRP sheets to strengthen RC beams. GFRP sheets could be effective in an increase of ductility. El-Gamal et al. [10] tested RC beams strengthened with CFRP and GFRP under bending load. It was found that 31-133\% increase in flexural capacity was obtained. Micelli et al. [11] studied $12 \mathrm{RC}$ beams strengthened with CFRP and AFRP. Experimental results showed an increase in ultimate strength capacity and flexural stiffness.

It is a challenging task to study and investigate reinforced concrete members numerically, because it involves a detailed description of a construction model, aiming to characterize the design and material properties with boundary conditions and loads $[12,13]$.

The first simulation study was made by Deskovic et al. [14]. They investigated the numerical shortterm behavior of an innovative FRP-concrete beam and the numerical results were compared with experimental graphs and analytical results. Nguyen [15] studied simulated hybrid beams with partial shear interaction. A GFRP-CFRP I-shaped profile and an ultra-high-performance fiber-reinforced concrete (UHPFRC) slabs were used in this project. The results showed the shear stress was underestimated due to the linear elastic FRP model that could fail to record progress damage. Liang et al. [16] modeled the concrete slab and it was defined as a thick shell element. They investigated the strength of steel-concrete composite beams and offered a method to evaluate the shear capacity of the slabs. Similarly, Ban and Bradford [17] used the finite element method to model composite beams with high-strength steel profiles. Numerical results indicated the load-deflection well fitted experimental results. Nie et al. [18] used solid finite elements for the definition of slabs and they analyzed the behavior of concrete slabs under negative bending. The numerical result and experimental response coincided. Correia et al. [19] analyzed and investigated the distribution of stress in hybrid slabs by using linear elastic behavior. Joseph et al. [20] investigated the behavior of concrete beams strengthened with FRP using experimental and numerical methods. They used Abaqus software to simulate the linear behavior of the beams. They suggested the use of coupled stiffness coefficients for modeling the cohesive interface.

Enochsson [21] modeled the CFRP strengthening of concrete slabs with openings in Abaqus software. After analyzing all models, debonding failure was seen in each model. Kim et al. [22] carried out a similar study. They modeled and analyzed the two-way reinforced concrete slabs with CFRP by using Ansys. Elsayed et al. simulated concrete slabs reinforced with concrete slabs and FRP laminates were defined as 3D brick and 2D shell, respectively in Abaqus software. Loo et al. [23] performed a numerical investigation of concrete hybrid slabs under shear pull-out tests. Hörmann et al. [24] investigated two nonlinear finite element models; two-dimensional (2D) and three-dimensional (3D) to study concrete slabs reinforced with FRP. Naser et al. [25] used three-dimensional (3D) FE modeling for the analysis of strengthened beams with CFRP laminate. The cohesion 3D 8-node element was applied for the bond between FRP and concrete surfaces. Noël and Soudki [26] used GFRP and CFRP to reinforce the concrete slab bridge. Experimental results indicated that the CFRP had a significant effect on serviceability and ultimate load-carrying capacity.

Regarding the kinds of FRP, carbon fiber reinforced polymer composite (CFRP) is light, strong and has high value among other FRPs. (GFRPs) glass fiber reinforced polymers sheets have negative aspects, including low elastic modulus and tensile strength in comparison with CFRP. But they have good deformability and break resistance. AFRP is another kind of FRP with high-strength and high-stiffness aromatic polyamide fibers. FRP composites have highlighted benefits mentioned. They lead to decreased long-term maintenance costs [27]. Hastak and Haplin [28] studied the cost of bridge columns reinforced with FRP and steel. Although the FRP-wrapping was more effective than steel jacketing in strengthening columns, FRP was more expensive by $20 \%$. Phillips et al. [29] evaluated the cost of FRP in concrete deck reinforced with GFRP bars for the Route 668 Bridge in Virginia. They calculated the average cost of GFRP bars and epoxy adhesive which was about $\$ 75 / \mathrm{m}^{2}$ and $\$ 29 / \mathrm{m}^{2}$, respectively. Berg et al. [30] stated that using FRP in bridge slab caused a $57 \%$ reduction in the total costs. Eamon et al. [31] reported that CFRP reinforcement used in the strengthening of concrete bridges could reduce all expenses considerably.

The purpose of this research is to study and investigate concrete hybrid slabs under bending load numerically as well as experimentally. Furthermore, the casting cost is calculated and analyzed for each specimen by considering different parameters; i.e., FRP type ,sand, stone, and GFRP mesh. Finally, this research attempts to provide design guidelines for cost-effective hybrid FRP-concrete slab elements which can derive the great benefits of FRP and hybrid steel-concrete slabs while overcoming steel sheet disadvantages. 


\section{Summary of experimental tests}

There were eight medium CFRP concrete slabs with different connections: glass girder mesh, stone, and sand to analyze the load-displacement in bending tests conducted by the authors. Each specimen was fabricated at the laboratory, having a dimension of $400 \mathrm{~mm} \times 75 \mathrm{~mm} \times 2000 \mathrm{~mm}$ as shown in Fig.1. For casting each specimen, commercial dry ready-mixed concrete [32] was used and the average compressive resistance was about 20.1MPa a non-destructive impact hammer test was made for each specimen. Masterbrace FIB $300 / 50$ fibers were impregnated with epoxy resin (Resoltech $1200+1204)$. The thickness of CFRP was $1.4 \mathrm{~mm}$.

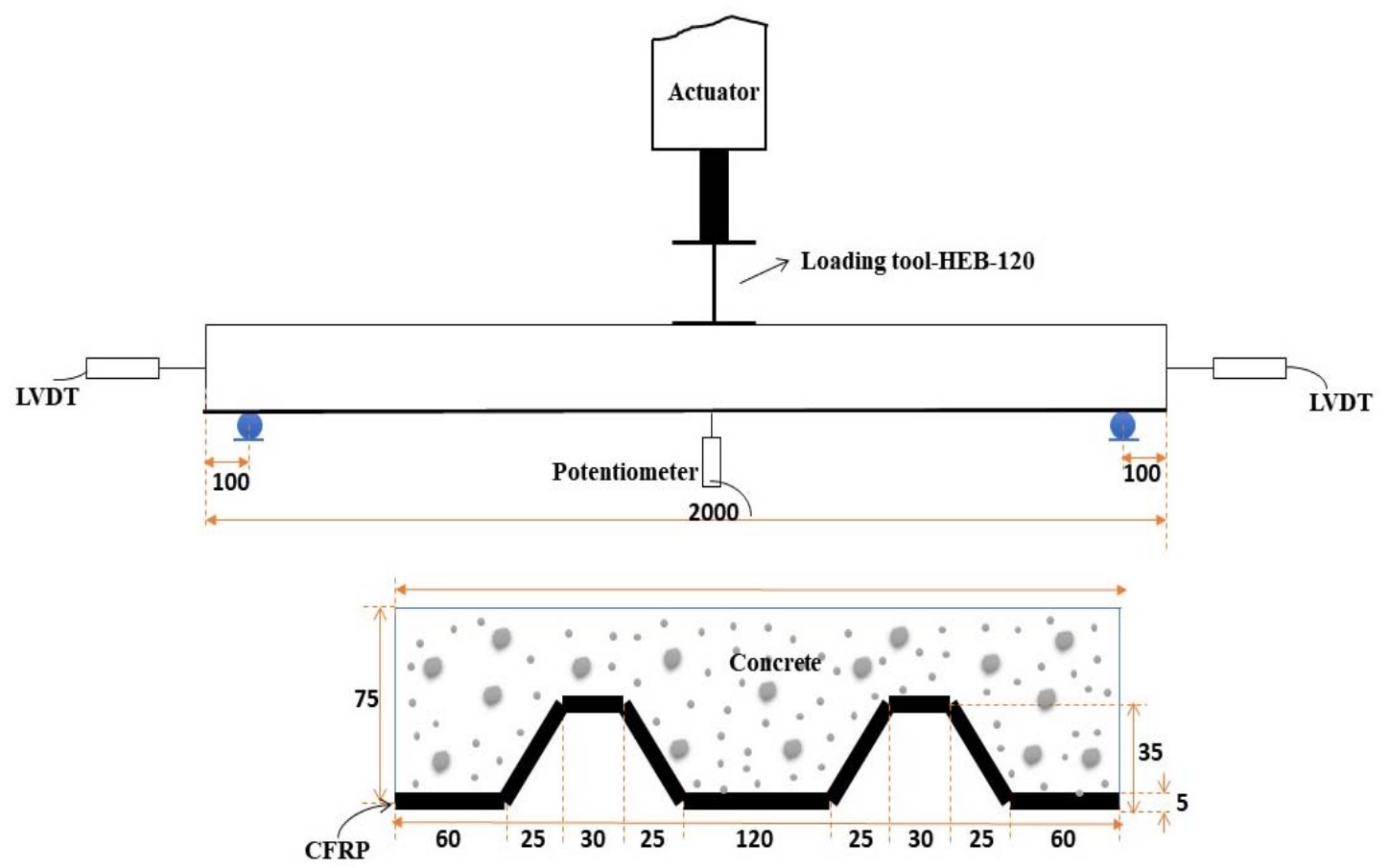

Fig.1. Test setup configuration and specimen's details (dimensions in $\mathrm{mm}$ ).

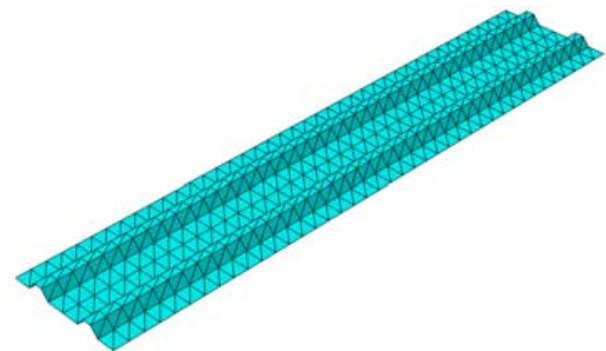

CFRP (M3D4R)

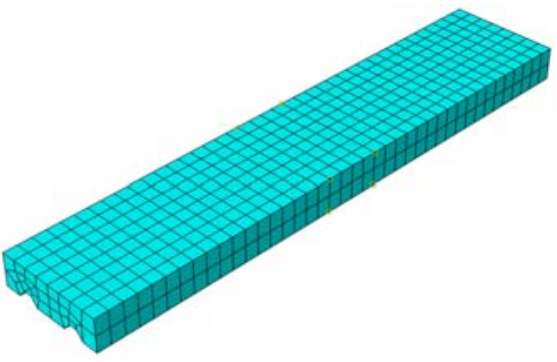

Concrete (C3D8R)

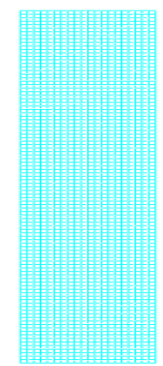

GFRP grid (T3D2)

Fig.2. Meshes.

The handmade CFRP had an average elastic modulus of $45.55 \mathrm{GPa}$ and an ultimate tensile strength of 1120MPa. Glass fiber grids (MapeGrid G220) were used and placed between CFRP and concrete as reinforcement. The grid spacing was a square $(20 \times 20)$. The weight of the grid was $225 \mathrm{gr} / \mathrm{m}^{2}$ and its tensile 
strength was $45 \mathrm{kN} / \mathrm{m}$. Sand and stone particles were used and placed on the inner part of the CFRP sheet and concrete in order to provide a frictional connection. The diameter of the sand was about $0-4 \mathrm{~mm}$ and the stone had a diameter of $5-12 \mathrm{~mm}$. Three-point bending tests were conducted on each specimen. Figure 1 shows the bending load that is applied at two points. The rate of imposed load was $1 \mathrm{~mm} / \mathrm{min}$, and was maintained until the failure happened, as shown in Fig.1. The free span was $1800 \mathrm{~mm}$. To measure the relative displacement of the slab, two external LVDT sensors were used with a $20 \mathrm{~mm}$ range and $0.2 \%$ linearity. There were two strain gauges and four wires placed under the CFRP sheet [33].

Table 1. Mechanical properties of the concrete and FRP

\begin{tabular}{|c|c|c|c|c|c|c|c|c|}
\hline Material & \multicolumn{8}{|c|}{ Parameters } \\
\hline \multirow{2}{*}{ concrete } & $\begin{array}{c}\text { Dilation } \\
\text { angle }\end{array}$ & Eccentricity & $f b_{0} / f c_{0}$ & $K$ & $\begin{array}{l}\text { Viscosity } \\
\text { parameter }\end{array}$ & $\rho\left(k g / m^{3}\right)$ & $E(G P a)$ & $v$ \\
\hline & 30 & 0.1 & 1.16 & 0.67 & 0.001 & 2350 & 10.737 & 0.3 \\
\hline \multirow[b]{2}{*}{ CFRP } & \multicolumn{2}{|c|}{$\rho\left(\mathrm{kg} / \mathrm{m}^{3}\right)$} & \multicolumn{3}{|c|}{$E(G P a)$} & \multicolumn{3}{|c|}{$v$} \\
\hline & \multicolumn{2}{|c|}{1800} & \multicolumn{3}{|c|}{455} & \multicolumn{3}{|c|}{0.3} \\
\hline GFRP & \multicolumn{2}{|c|}{1800} & \multicolumn{3}{|c|}{72} & \multicolumn{3}{|c|}{0.3} \\
\hline AFRP & \multicolumn{2}{|c|}{1800} & \multicolumn{3}{|c|}{52} & \multicolumn{3}{|c|}{0.34} \\
\hline
\end{tabular}
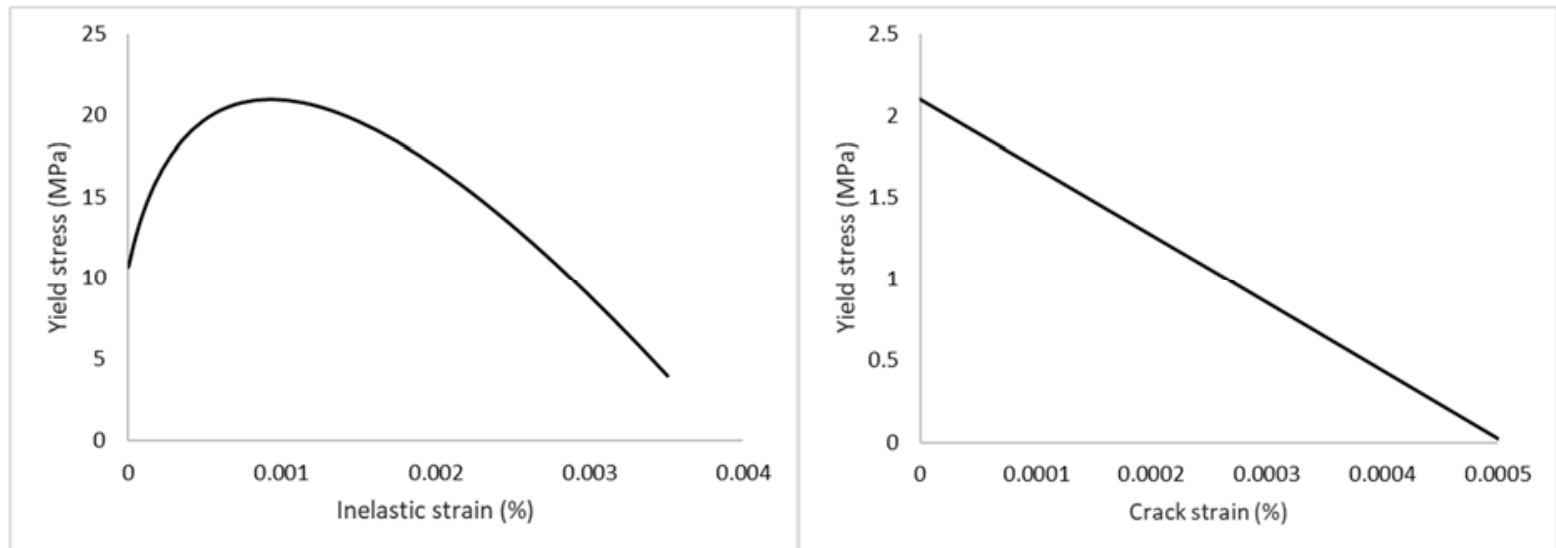

Fig.3. Uniaxial behavior of concrete in tension and compression [34].

\section{Numerical simulations}

This part explains the numerical procedure and validation in the finite element method (FEM) which is performed using the ABAQUS $2017 \AA$ to investigate the behavior of concrete hybrid slabs under bending test. First of all, the constitutive models for concrete and all reinforcements with details are presented, and this section states the mechanical properties, boundary conditions, and mesh. Finally, the validation of the numerical model was evaluated and checked by experimental results from hybrid concrete slab tests performed by the authors.

\subsection{Modelling procedures}

Abaqus constructed (3D) three-dimensional models and three types of elements were used: solid, shell, and truss. A three-dimensional eight-node linear brick element with reduced integration and hourglass control (C3D8R) was used for the definition of a specimen concrete omega slab shape [35]. The GFRP mesh grid was defined as a two-node linear 3D truss element (T3D2) with three degrees of freedom at each node [36]. 
A 4-node element with a linear quadrilateral (S4R) was used for the FRP (CFRP, GFRP, and AFRP) layer [37]. The mesh size sensitivity for all parts was defined as dependent and the maximum seed dimension of each part was $5 \mathrm{~cm}$. The details of the finite element mesh are shown in Fig.2. In terms of mechanical properties, concrete was defined and modeled as a homogeneous isotropic material with a combination of elastic-plastic plots in two parameters: compression and tension behavior. Furthermore, Young's modulus and Poisson's rate of used concrete were defined. The largest distinction in material modeling was linked to the nonlinear behavior of concrete. Concrete-damaged plasticity with concrete compression damage and concrete tension damage were used for the nonlinear analysis of concrete members. Table 1 shows the mechanical properties of concrete and FRP. Figure 3 presents the average compressive behavior curve of concrete and the tensile behavior curve of the concrete formulations used in the manufacture of hybrid slabs [34]. The reinforcements were modeled and defined using different techniques in the Abaqus software. The embedded region constraint was modeled and the truss element (GFRP mesh) was connected to the 3D element (concrete). Concrete was defined as a host region and GFRP mesh was an embedded region in this constraint [38]. Two comprehensive numerical outputs were extracted: force-displacement curve and maximum plastic strain index.

\subsection{Validation against the author's experimental result}

Figure 4 compares the force-displacement curve between the numerical model and the experimental specimen for one representative specimen with a connection glass fiber mesh. In this figure, one of the simulation aims was to see how well the numerical result matched with experimental findings. The difference between the two terms is less than $15 \%$. It is noted that the numerical response practically overlaps the laboratory result, but the ultimate displacement was different for both responses; $34.9 \mathrm{~mm}$ for numerical analysis and $29.5 \mathrm{~mm}$ for experimental study.

\subsection{Parametric study}

The different geometries with different types of FRP were used to perform several parametric studies on FRP hybrid concrete slabs. The effects of several parameters on the force-displacement curve and maximum plastic strain were investigated. Additionally, the effect of geometries and FRP type on cast costs were analyzed. As shown in Fig.5. four types of FRP position are defined for models. In model A, the area of FRP is equal to all bottom surfaces of the concrete. In model $\mathrm{B}$, the area of FRP is equal to all bottom surfaces of the concrete plus longitudinal and transverse edges from the bottom until the top. In model C, the area of FRP is equal to all bottom surfaces of the concrete plus longitudinal edges from the bottom until the top. In model $\mathrm{D}$, the area of FRP is equal to the area of the concrete top hat sections.

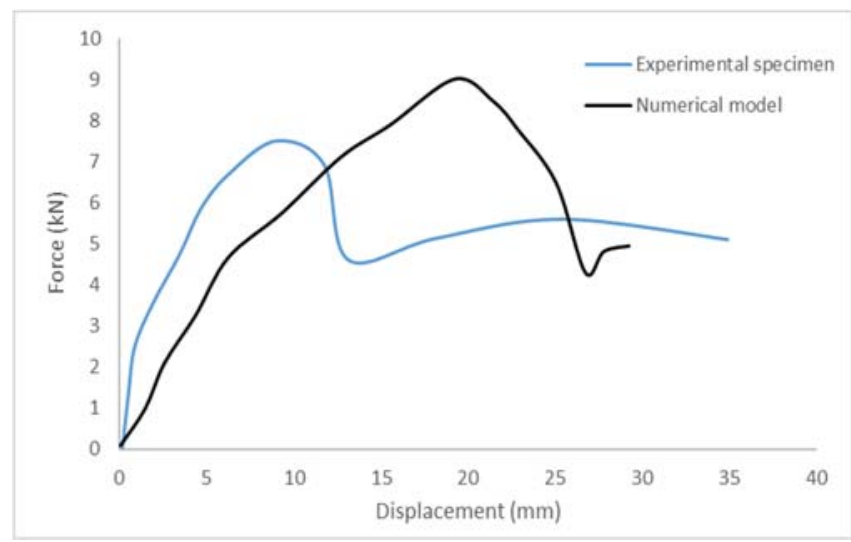

(a)

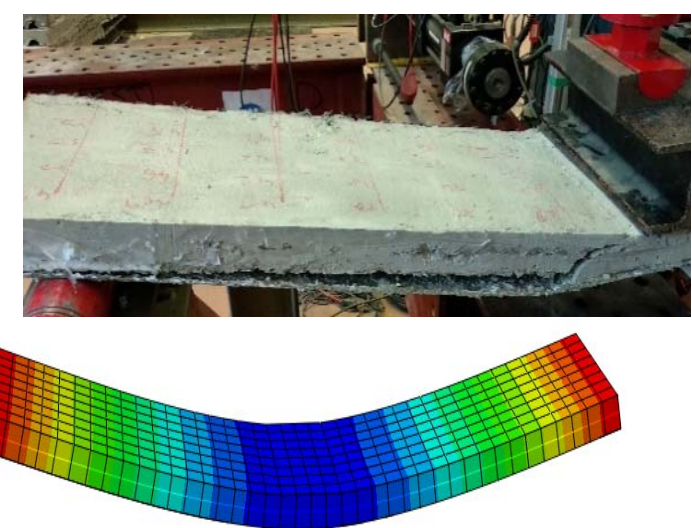

(b)

Fig.4. Comparison between the numerical model and experimental specimen; a) force-displacement curve; b) the slab after bending test. 


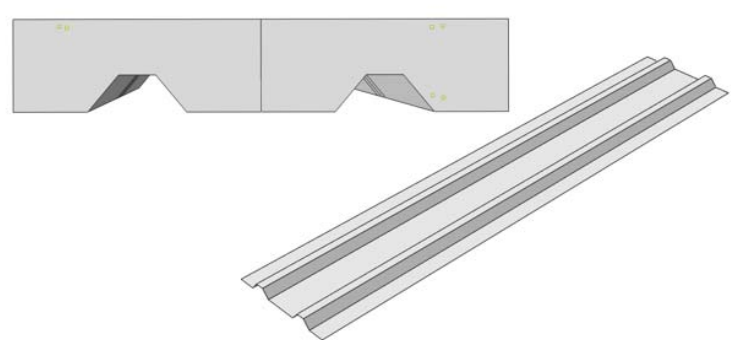

Case A. one layer of underside FRP

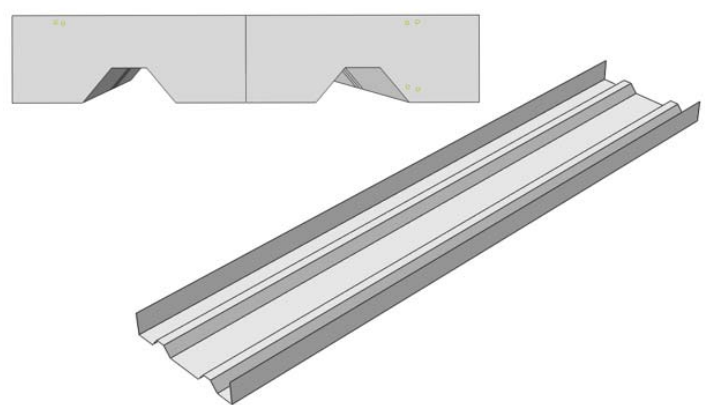

Case C. one layer of underside and two besides FRP in the longitudinal direction

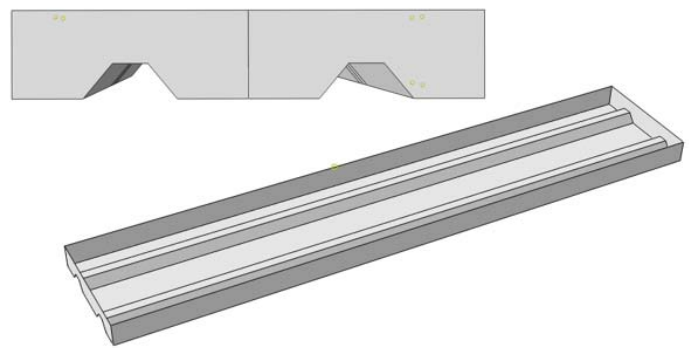

Case B. one layer of the underside and beside FRP

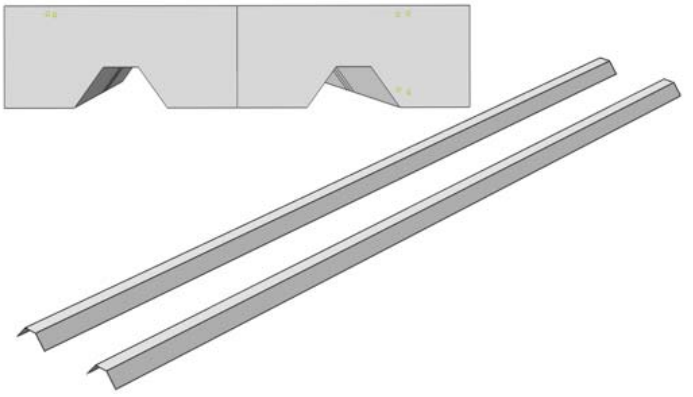

Case D. one layer of underside FRP only omega-shaped reinforced

Fig.5. Numerical models.

\section{Numerical results}

Primarily, the general flexural behavior of the four models was analyzed. Figure 6 compares the forcedisplacement curves of cases A, B, C and D in three types of FRP obtained from the numerical investigation. According to case A results, the ultimate forces of CFRP, GFRP, and AFRP are respectively 9.01, 8.01, and $7.84 \mathrm{kN}$, so CFRP showed a better result in this case. Regarding case B results, the maximum forces of $\mathrm{C}, \mathrm{G}$, and AFRP are 7.78, 7.83, and 7.68kN. AFRP presents a better performance in case B. Depending on case C, the final forces of $\mathrm{C}, \mathrm{G}$, and AFRP are 7.73, 8.22, and 7.97, respectively. GFRP is the best choice in the case of C. According to case D, the ultimate forces of C, G, and AFRP are 5.77, 7.29, and 6.07 in order. GFRP performed better than others in case D.

Regarding force-displacement curves of FRPs in four different cases, it is clear that results in cases A, $\mathrm{B}$, and $\mathrm{C}$ are in the same range because adding FRPs to the longitudinal and transverse edges of the hybrid elements does not have an impressive effect on the bending results, because in three-point bending tests the high-pressure spreads in the bottom surface of the composite, especially in the middle, and tries to break the slab in vertical pressing. On the other hand, as can be seen from the plots, results in case D showed a notable reduction in comparison to other cases because an important part of the slab, which is an area at the bottom surface between top hats, is not reinforced by the FRPs and the reinforcing area on the bottom side is not consistent in this case.

According to Fig.7., which shows the ultimate principal plastic strain for all numerical cases, the maximum plastic strain shown by the FRPs in case A belongs to GFRP and in other cases belongs to GFRP and AFRP jointly. The exact numbers are presented in Fig.7. 


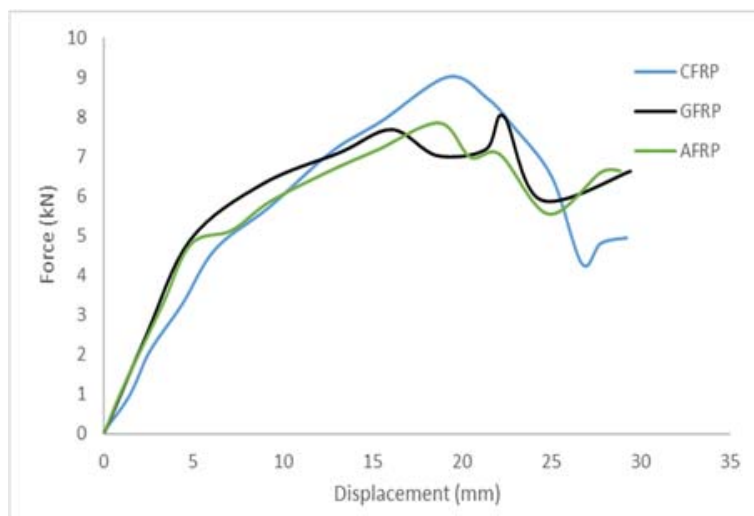

Case A.

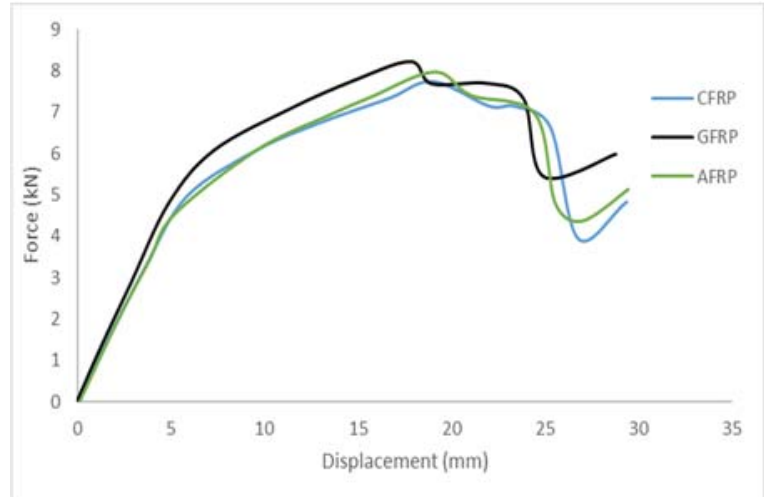

Case C.

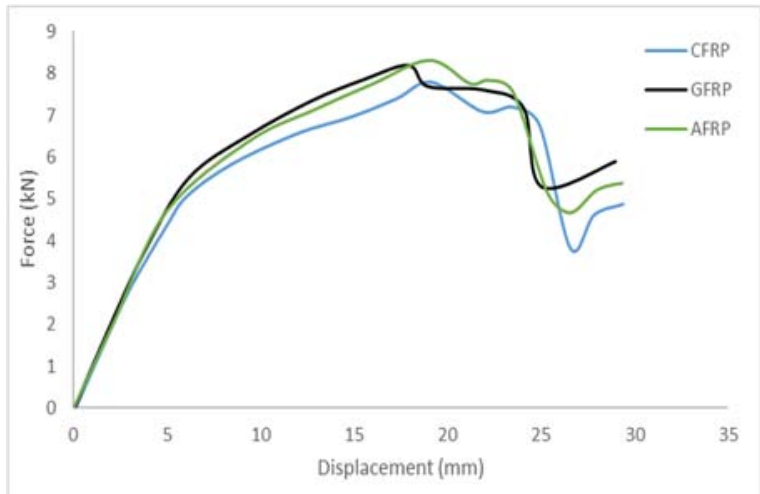

Case B.

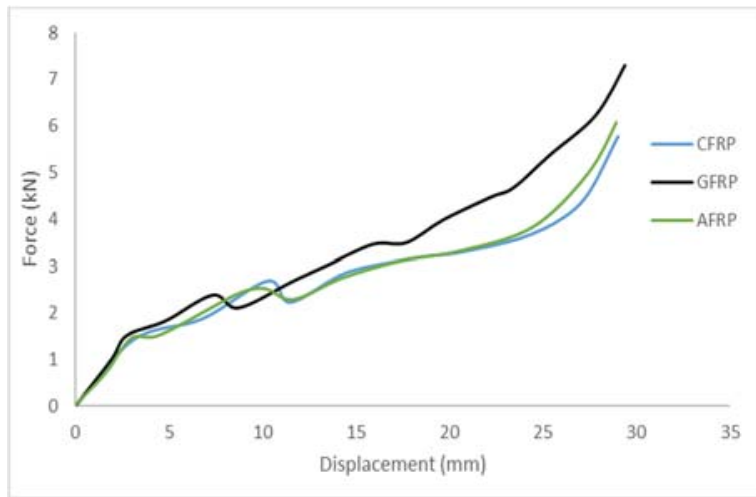

Case D.

Fig.6. Comparison of Force-Displacement curves for all cases.

\begin{tabular}{|c|c|c|c|}
\hline \multirow[t]{2}{*}{ Model } & CFRP & GFRP & AFRP \\
\hline & $\operatorname{Max}(P E)=1.18 \%$ & $\operatorname{Max}(P E)=1.24 \%$ & $\operatorname{Max}(P E)=1.22 \%$ \\
\hline \multicolumn{4}{|l|}{ Case. A } \\
\hline & $\operatorname{Max}(P E)=1.22 \%$ & $\operatorname{Max}(P E)=1.25 \%$ & $\operatorname{Max}(P E)=1.25 \%$ \\
\hline \multicolumn{4}{|l|}{ Case. B } \\
\hline & $\operatorname{Max}(P E)=1.21 \%$ & $\operatorname{Max}(P E)=1.25 \%$ & $\operatorname{Max}(P E)=1.25 \%$ \\
\hline \multicolumn{4}{|l|}{ Case. $\mathrm{C}$} \\
\hline & $\operatorname{Max}(P E)=0.92 \%$ & $\operatorname{Max}(P E)=0.97 \%$ & $\operatorname{Max}(P E)=0.97 \%$ \\
\hline
\end{tabular}

Fig.7. Maximum principal plastic strain for all cases. 


\section{Construction costs}

After the simulation of hybrid concrete slabs, financial data on the cast slabs was collected to provide a comparison of all numerical models. The total material costs for all components are shown in Table 2. All financial data was received by Omran Sanaat Ava company at the author's request. Due to the fact that these numerical models are simulated in the Abaqus software, miscellaneous expenses such as labor and transportation costs have been neglected. Additionally, the cost of resin adhesive is not considered. The cost of the casting numerical model is between $\$ 22$ and $\$ 42$ according to the calculations in Table 2. The minimum value and maximum value for making models are related to Case D (GFRP) and Case B (CFRP). Fig.8. compares the construction cost among the numerical models.

Table 2. Estimated costs for all material.

\begin{tabular}{|c|c|c|c|c|c|c|c|c|c|c|c|}
\hline \multirow[t]{2}{*}{ Model } & \multicolumn{2}{|c|}{ AFRP } & \multicolumn{2}{|c|}{ GFRP } & \multicolumn{2}{|c|}{ CFRP } & \multicolumn{2}{|c|}{ Concrete } & \multicolumn{2}{|c|}{ GFRP mesh } & \multirow{2}{*}{$\begin{array}{c}\text { Total } \\
\text { cost }\end{array}$} \\
\hline & $\begin{array}{c}U . P \\
\left(\$ / m^{2}\right)\end{array}$ & $\begin{array}{c}Q \\
\left(m^{2}\right)\end{array}$ & $\begin{array}{c}U . P \\
\left(\$ / m^{2}\right)\end{array}$ & $\begin{array}{c}Q \\
\left(\mathrm{~m}^{2}\right)\end{array}$ & $\begin{array}{c}U . P \\
\left(\$ / m^{2}\right)\end{array}$ & $\begin{array}{c}Q \\
\left(m^{2}\right)\end{array}$ & $\begin{array}{c}U . P \\
\left(\$ / m^{3}\right)\end{array}$ & $\begin{array}{c}Q \\
\left(\mathrm{~m}^{3}\right)\end{array}$ & $\begin{array}{c}U . P \\
\left(\$ / m^{2}\right)\end{array}$ & $Q\left(m^{2}\right)$ & \\
\hline $\begin{array}{c}\text { Case } \\
\text { A }\end{array}$ & 13 & 1.04 & 7.5 & 1.04 & 17 & 1.04 & & & & & $\begin{array}{c}35.58 \\
25.7 \\
31.42\end{array}$ \\
\hline $\begin{array}{c}\text { Case } \\
\text { B }\end{array}$ & 13 & 1.39 & 7.5 & 1.39 & 17 & 1.39 & 118 & 0.05 & 15 & 0.8 & $\begin{array}{l}41.53 \\
28.32 \\
35.97\end{array}$ \\
\hline $\begin{array}{c}\text { Case } \\
\text { C }\end{array}$ & 13 & 1.34 & 7.5 & 1.34 & 17 & 1.34 & & & & & $\begin{array}{l}40.68 \\
27.95 \\
35.32\end{array}$ \\
\hline $\begin{array}{c}\text { Case } \\
\text { D }\end{array}$ & 13 & 0.56 & 7.5 & 0.56 & 17 & 0.56 & & & & & $\begin{array}{c}27.42 \\
22.1 \\
25.18\end{array}$ \\
\hline
\end{tabular}

Here U.P - Unit price, Q - Quantity

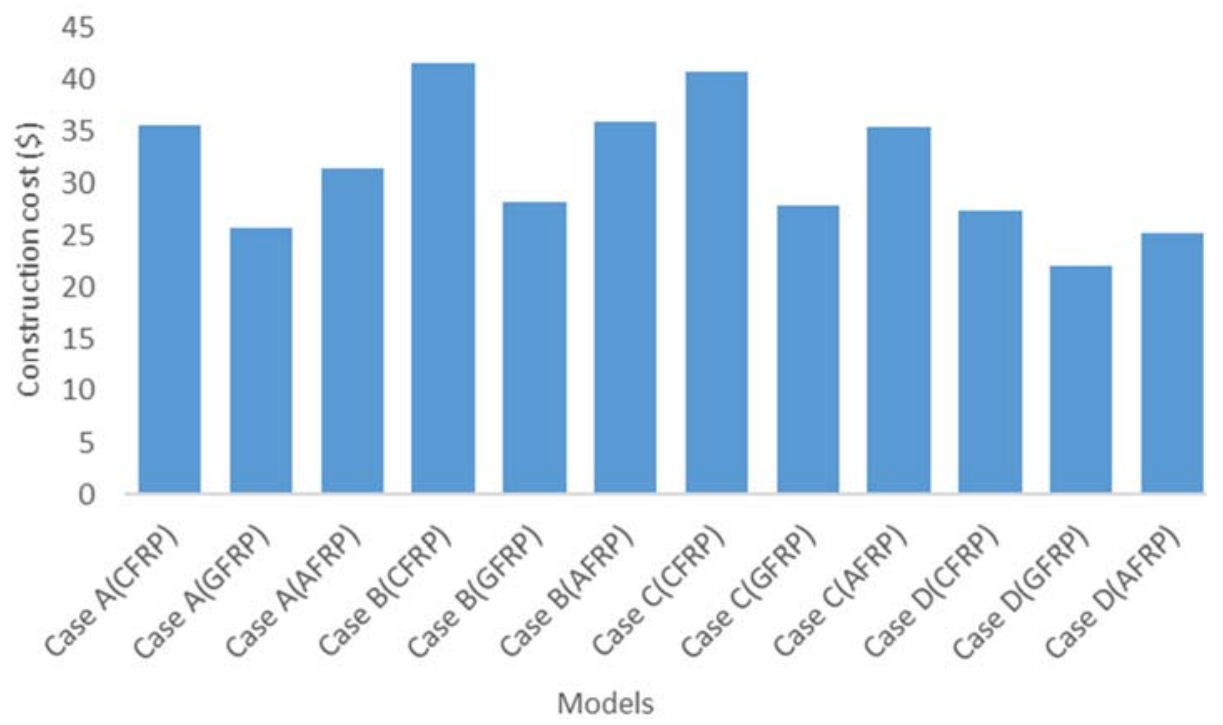

Fig.8. construction cost for all models. 


\section{Conclusion}

A detailed numerical analysis was performed to examine the efficiency of the concrete top hat slab framework with three forms of fiber-reinforced polymers (FRPs) such as CFRP, GFRP, and AFRP sheets attached to concrete by a glass fiber mesh. Four types of models with different positions and usage of each FRP were simulated. One of these was used to match model parameters with usable experimental outcomes, while the others were used to evaluate optimal and feasible alternate design solutions. The following conclusions can be drawn from the results:

1. The proposed model fitted full experimental force-displacement curves with a slight underestimation of the maximum load-bearing capacity of less than $15 \%$.

2. The position and amount of the FRPs' usage are the most sensitive parameters to be adjusted in the model.

3. Adding the FRPs to the edges of hybrid elements did not provide greater load-bearing capacity and the most important area of concrete for reinforcing is the omega shape area.

4. The loss of bottom FRP plates was directly linked to a reduction in the load-bearing capacity, an increase in tensile concrete damage, and a reduction in stiffness since the tensile stress had to be borne more by the concrete in this situation.

5. AFRP and GFRP showed similar results and both were better than CFRP. However, GFRP performed around $5 \%$ better than AFRP in the case of the technical report.

6. Under calculations, Case D (GFRP) has a minimum cost for casting in comparison to other models.

\section{Nomenclature}

$$
\begin{aligned}
E & - \text { Young's modulus } \\
\rho & - \text { density } \\
v & - \text { Poisson's rate } \\
f b_{0} & - \text { equiaxial compressive strength of concrete } \\
f c_{0} & - \text { uniaxial compressive strength of concrete } \\
K & - \text { hardening/softening criterion }
\end{aligned}
$$

\section{References}

[1] Al-Rousan R.Z., Alhassan M.A., and Al-Salman H. (2017): Impact resistance of polypropylene fiber reinforced concrete two-way slabs.- Struct. Eng. Mech., vol.62, No.3, pp.373-380, doi:10.12989/sem.2017.62.3.373.

[2] Yılmaz T., Kıraç N., Anil Ö., Erdem R.T. and Sezer C. (2018): Low-velocity impact behaviour of two way RC slab strengthening with CFRP strips.- Constr. Build. Mater., vol.186, pp.1046-1063, doi:10.1016/j.conbuildmat.2018.08.027.

[3] Abed F. and Alhafiz A.R. (2019): Effect of basalt fibers on the flexural behavior of concrete beams reinforced with BFRP bars.- Compos. Struct., vol.215, pp.23-34, doi: 10.1016/j.compstruct.2019.02.050.

[4] Mahboob A., Gil L., Bernat-Maso E. and Eskenati A.R. (2021): Experimental and numerical study of shear interface response of hybrid thin CFRP-Concrete slabs.- Materials (Basel), vol.14, No.18, doi:10.3390/ma14185184.

[5] Eskenati A.R., Mahboob A., Alirezaie A., Askari R. and Kolbadi S.M.S. (2021): Investigating the effect of longitudinal gallery on dynamical response of gravity concrete dams using fem.- J. South. Jiao. Uni. vol.56, pp.804-811, doi:10.35741/issn.0258-2724.56.4.69.

[6] Fam A. and Rizkalla S. (2003): Large scale testing and analysis of hybrid concrete/composite tubes for circular beamcolumn applications.- Constr. Build. Mater., vol.17, No.6-7, pp.507-516, doi: 10.1016/S0950-0618(03)00048-5.

[7] Ebead U. and Marzouk H. (2004): Fiber-reinforced polymer strengthening of two-way slabs.- ACI Struct. J., vol.101, No.4, pp.650-669, doi: 10.14359/13387.

[8] Toutanji H., Zhao L. and Zhang Y. (2006): Flexural behavior of reinforced concrete beams externally strengthened with CFRP sheets bonded with an inorganic matrix.- Eng. Struct., vol.28, No.4, pp.557-566, doi: 
10.1016/j.engstruct.2005.09.011.

[9] Hawileh R.A., H.A. Rasheed, J.A. Abdalla and A.K. Al-Tamimi (2014): Behavior of reinforced concrete beams strengthened with externally bonded hybrid fiber reinforced polymer systems.- Mater. Des., vol.53, pp.972-982, doi: 10.1016/j.matdes.2013.07.087.

[10] El-Gamal S.E., Al-Nuaimi A., Al-Saidy A. and Al-Lawati A. (2016): Efficiency of near surface mounted technique using fiber reinforced polymers for the flexural strengthening of RC beams.- Constr. Build. Mater., vol.118, pp.5262, doi: 10.1016/j.conbuildmat.2016.04.152.

[11] Micelli F., Annaiah R.H. and Antonio N. (2002): Strengthening of short shear span reinforced concrete T joists with fiber-reinforced plasic composites.- J. Compos. Constr., vol.6, No.4, pp.264-271, doi: 10.1061/(ASCE)10900268(2002)6:4(264).

[12] Rabczuk T., Akkermann J. and Eibl J. (2005): A numerical model for reinforced concrete structures. -Int. J. Solids Struct., vol.42, No.5-6, pp.1327-1354, doi: 10.1016/j.ijsolstr.2004.07.019.

[13] Rabczuk T. and Eibl J. (2004): Numerical analysis of prestressed concrete beams using a coupled element free Galerkin/finite element approach.- Int. J. Solids Struct., vol.41, No.3-4, pp.1061-1080, doi: 10.1016/j.ijsolstr.2003.09.040.

[14] Nikola D., Triantafillou T.C. and Urs M. (1995): Innovative design of FRP Combined with concrete: short-term behavior.- J. Struct. Eng., vol.121, No.7, pp.1069-1078, doi: 10.1061/(ASCE)0733-9445(1995)121:7(1069).

[15] Nguyen H., Mutsuyoshi H. and Zatar W. (2015): Hybrid FRP-UHPFRC composite girders: Part 1 - experimental and numerical approach.- Compos. Struct., vol.125, pp.631-652, doi: 10.1016/j.compstruct.2014.10.038.

[16] Liang Q.Q., Uy B., Bradford M.A. and Ronagh H.R. (2005): Strength analysis of steel-concrete composite beams in combined bending and shear.- J. Struct. Eng., vol.131, No.10, pp.1593-1600, doi: 10.1061/(ASCE)07339445(2005)131:10(1593).

[17] Ban H. and Bradford M.A. (2013): Flexural behaviour of composite beams with high strength steel.- Eng. Struct., vol.56, pp.1130-1141, doi: 10.1016/j.engstruct.2013.06.040.

[18] Nie J., Fan J. and Cai C.S. (2004): Stiffness and deflection of steel-concrete composite beams under negative bending.- J. Struct. Eng., vol.130, No.11, pp.1842-1851, doi: 10.1061/(ASCE)0733-9445(2004)130:11(1842).

[19] Correia J.R., Branco F.A. and Ferreira J.G. (2007): Flexural behaviour of GFRP-concrete hybrid beams with interconnection slip.- Compos. Struct., vol.77, No.1, pp.66-78, doi: 10.1016/j.compstruct.2005.06.003.

[20] Joseph R.J. and Silvakumar P. (2011): Linear Behaviour of carbon fibre reinforced polymer plate bonded beam.-- in International conference on emerging Technology Trends (ICETT), International Journal of Computer Applications (IJCA), pp.1-6.

[21] Enochsson Ola (2005): CFRP Strengthening of Concrete Slabs, with and without Openings.- Luleå University of Technology.

[22] Kim Y.J., Longworth J.M.,Wight R.G and Green M.F (2008): Flexure of Two-way slabs strengthened with prestressed or nonprestressed CFRP sheets.- J. Compos. Constr., vol.12, No.4, pp.366-374, doi: 10.1061/(ASCE)1090-0268(2008)12:4(366).

[23] Loo K.Y.M, Foster S.J. and Smith S.T. (2012): FE modeling of CFRP-repaired RC Beams subjected to fatigue loading.- J. Compos. Constr., vol.16, No.5, pp.572-580, doi: 10.1061/(ASCE)CC.1943-5614.0000286.

[24] Hörmann M., Menrath H. and Ramm E. (2002): Numerical investigation of fiber reinforced polymers poststrengthened concrete slabs.- J. Eng. Mech., vol.128, No.5, pp.552-561, doi: 10.1061/(ASCE)07339399(2002)128:5(552).

[25] Naser M., Hawileh R., Abdalla J.A. and Al-Tamimi A. (2012): Bond behavior of CFRP cured laminates: experimental and numerical investigation.- J. Eng. Mater. Technol., vol.134, No.2, pp.021002-021010, doi: 10.1115/1.4003565.

[26] Martin N.and Khaled S. (2013): Effect of prestressing on the performance of GFRP-Reinforced concrete slab bridge strips.- J. Compos. Constr., vol.17, No.2, pp.188-196, doi: 10.1061/(ASCE)CC.1943-5614.0000326.

[27] Taketo U., Hiroshi M., Futoshi K. and Sudhir M. (2002): Use of Fiber reinforced polymer composites as reinforcing material for concrete.- J. Mater. Civ. Eng., vol.14, No.3, pp.191-209, doi: 10.1061/(ASCE)08991561(2002)14:3(191).

[28] Makarand H. and Halpin D.W. (2000): Assessment of life-cycle benefit-cost of composites in construction.- J. Compos. Constr., vol.4, No.3, pp.103-111, doi: 10.1061/(ASCE)1090-0268(2000)4:3(103). 
[29] Phillips K.A., Harlan M., Roberts-Wollmann C.L. and Cousins T.E. (2005): Performance of a Bridge Deck with Glass Fiber Reinforced Polymer Bars as the Top Mat of Reinforcement.- Virginia Transportation Research Council.

[30] Berg A.C., Bank L.C., Oliva M.G. and Russell J.S. (2006): Construction and cost analysis of an FRP reinforced concrete bridge deck.- Constr. Build. Mater., vol.20, No.8, pp.515-526, doi: 10.1016/j.conbuildmat.2005.02.007.

[31] Eamon C.D., Jensen E.A., Grace N.F. and Xiuwei S. (2012): Life-cycle cost analysis of alternative reinforcement materials for bridge superstructures considering cost and maintenance uncertainties.- J. Mater. Civ. Eng., vol.24, No.4, pp.373-380, doi: 10.1061/(ASCE)MT.1943-5533.0000398.

[32] American Society for Testing and Materials (2002): American Society for Testing and Materials. ASTM C805-02 Standard Test Method for Rebound Number of Hardened Concrete.- Am. Soc. Test. Mater.

[33] Mahboob A., Gil L., Bernat-Maso E. and Eskenati A.R. (2021): Flexible fiber fabric for FRP-concrete connection of thin hybrid slabs.- Polymers (Basel), vol.13, No.17, doi:10.3390/polym13172862.

[34] Vilanova I., Torres L., Baena M. and Llorens M. (2016): Numerical simulation of bond-slip interface and tension stiffening in GFRP RC tensile elements.- Compos. Struct., vol.153, pp.504-513, doi: 10.1016/j.compstruct.2016.06.048.

[35] Genikomsou A. and Polak M.A. (2017): Finite element simulation of concrete slabs with various placement and amount of shear bolts.- Procedia Eng., vol.193, pp.313-320, doi:10.1016/j.proeng.2017.06.219.

[36] Liu Y., Lenz T., Goldack A. and Schlaich M. (2013): Study on the flexural behaviour of CFRP-grid reinforced concrete one-way slabs. -Proc. 4th Asia-Pacific Conf. FRP Struct. APFIS 2013, pp.11-13.

[37] Raza A., Masood B. and Hussain I. (2020): Finite element modelling and theoretical predictions of FRP-reinforced concrete columns confined with various FRP-tubes.- Structures, vol.26, pp.626-638, 2020, doi: 10.1016/j.istruc.2020.04.033.

[38] Sharaky I.A., Baena M., Barris C., Sallam H.E.M. and Torres L. (2018): Effect of axial stiffness of NSM FRP reinforcement and concrete cover confinement on flexural behaviour of strengthened RC beams: experimental and numerical study.- Eng. Struct., vol.173, pp.987-1001, doi:10.1016/j.engstruct.2018.07.062.

Received: August 23, 2021

Revised: $\quad$ October 24, 2021 